\title{
Cost Minimization Techniques: A Case of Dairy Product Manufacturers in Pakistan
}

\author{
Usamah Iyyaz Billah \\ Hailey College of Commerce, University of the Punjab, Lahore, Pakistan \\ usamahbillah@yahoo.com
}

\begin{abstract}
One of the key challenges faced by manufacturing concerns in Pakistan is maintaining (or preferably increasing) the profitability level of their operations. For the purpose of this descriptive study, the dairy sector of Pakistan has been selected as a sample industry. The literature review explains why the dairy sector has been selected for this research, the key cost components and why cost minimization is necessary for companies manufacturing dairy products in Pakistan. A primary survey has been conducted with managers in top dairy companies of Pakistan and the findings have been discussed in detail. The findings include identification of cost components and their impact, cost minimization techniques and their impact on profitability as well as suggestions for new cost reduction measures. This research article is the first one conducted on this topic in Pakistan and can also open new avenues for further research in this area.
\end{abstract}

Keywords: Cost, minimization, reduction, profits, techniques, components, dairy, milk

\section{Introduction}

In the current economic scenario of Pakistan, inflation is not only a key issue for end consumers but also for most manufacturing concerns. Rising costs of raw material, packaging material, labor wages, fuel and overheads results in a decreasing bottom line for companies (Sherani, 2010). On the other hand, end consumers are also faced with the key economic problem of limited income and high expenses (Sherani, 2010). With the above context in mind, the targeted industry for this study is the dairy product manufacturing industry; whereby the key reasons for selection of this industry are given in the literature review. In light of credible references, the literature review shall aim to reaffirm the assumption that companies are facing cost pressures, the reasons for selection of dairy industry as a sample industry, the key cost factors in the dairy industry and why cost minimization is a primary requirement of decision makers in this industry. Through a primary research survey with decision makers in leading dairy companies of Pakistan, this research article shall explore the key cost factors/determinants involved in the dairy industry, the cost minimization techniques used by companies in this industry and acquire suggestions for further improvement. Apart from useful research implications, this article can also serve as a valuable guideline for decision makers \& practitioners in the dairy industry.

\section{Literature Review}

A number of studies have shown that while the western world has recently been in the grip of economic recession, Pakistan has been facing its own set of challenges including a low literacy rate, high unemployment, increasing population \& high inflation (Sherani, 2010). Furthermore, the purchasing power of consumers has also decreased due to limited incomes and an increasing cost of living (Sherani, 2010). In this scenario, companies in almost all industries are facing a consistent increase in their manufacturing costs due to increasing prices of fuel, raw material, packaging material and overheads; hence decreasing their profit earnings (Grossberg, 2009). It is also noteworthy to mention that profit ratios of companies are thin, inspite of taking regular price increases on the products. This incapability to increase prices to recover costs causes decline in the bottom line of many manufacturing concerns (Grossberg, 2009). Hence, it is advisable for companies to take significant cost reductions through long term planning and calculated decisions on a timely basis (Berman, Davidson, Longworth \& Blitz, 2009). With the above view in mind, a sample industry has been selected for this study. The selected industry is the dairy product manufacturing industry of Pakistan as it is one of the leading industries of the country. Let us see why: Agriculture contributes $20.9 \%$ of the total gross domestic product and provides employment to $43.4 \%$ of the total labor force in Pakistan (Zia, 2007). With approximately 50\% contribution, livestock is certainly the most significant sub-sector. The role of livestock is evident from the fact that approximately 35 million people are involved in raising 3 to 4 cows/buffaloes and 4 to 5 goats in their backyard and are generating 15 to $20 \%$ of their earnings from it (Afzal, 2006). Livestock 
also generates substantial national exports and 8.5 - 9.0\% of total exports stem from this sector (Afzal, 2006). Furthermore, the demand is increasing for livestock products due to increased consumer awareness of natural products and new investment opportunities are also arising (Afzal, 2006).

Within the livestock sector, milk is the commodity with the largest volume and production. It is estimated that yearly milk production of Pakistan is 29 million tons, making Pakistan the fifth largest producer of milk in the world (Fakhar, 2006). The annual value of total milk production (unbranded + branded) is Rs. 390 Billion (Zia, 2007). It is also noteworthy to mention that although Pakistan has a tremendous production of milk, the country is spending around $\$ 40$ million per annum on the import of formula (powder) milk only, which is a high amount for any developing country (Rizvi, 2002). Presently, there are numerous brands of infant powder milk available in the market. This fact demonstrates the exceptionally high demand for milk in Pakistan. A look into the branded milk segment shows that Tetra Pak products represent more than $90 \%$ of the branded milk industry of the country (TetraPak, 2010). This industry has a volume of approximately 760 million Ltr's/annum (TetraPak, 2010) \& an approximate value of Rs. 45 Billion/annum. It can be safely stated that Pakistan, being an emerging market is one of the leaders of growth in the global dairy industry (Dawn, 2011). Other Markets including China, India and the Middle East, are also witnessing swift growth in the demand of milk and other dairy products due to increasing populations, changing consumer preferences, increasing per capita incomes, and more awareness about the benefits of dairy products (Dawn, 2011). Currently, there are several dairy processing plants operating in the country. Dairy product manufacturers use fresh milk as a raw material to develop different kinds of processed milk for example, ultra heat treated (UHT) milk, pasteurized milk, tea creamers, skimmed milk, powder milk, etc. Further value added products like butter, yogurt, cheese, butter oil and cream are also produced from the fresh milk. The UHT technology, although expensive, has proven to be successful in Pakistan as it enhances the milk's shelf life to twelve weeks (Rizvi, 2002).

Regarding usage of milk products, it is estimated that the daily consumption of milk (branded + unbranded) in Lahore is around 2 to 3 million litres and that of Karachi is approximately 4 million litres (Pakissan, 2011). The need for packaged milk has also increased its share in upper income consumers, especially in urban centres. Over the last decade, packaged milk has increased to $4 \%$ share in the milk market of Lahore, which is expected to reach $4.5 \%$ within the next few years. Therefore, urban cities are the main markets for the trading of milk while semi urban areas are also gradually developing. On the international front, there is huge consumption of both liquid and dry milk in countries like India, UAE, KSA, Iran, Philippines and Malaysia. Pakistan can successfully use this as an advantage, if proper attention is paid to this industry. However, the dairy sector of Pakistan faces immense challenges including farm up gradation through improved profitability, better infrastructure and improving the quality of raw milk collection (Dawn, 2011). Now, we shall discuss some reasons why cost minimization is a primary requirement for dairy product manufacturers and the significant cost components. Firstly, in the highly competitive market, it has become vital for companies to ensure that they manufacture the right products and ensure availability to the consumers at the right time while keeping the logistics and production costs to a minimum (Sher, 2010). However, dairy products are swiftly becoming costlier as farming of live stock has not scientifically improved in quantity and quality. Further, it has not kept pace with the rapid increase in population and urbanization. Secondly, due to rising inflation and high poverty levels, the majority of Pakistani consumers are price conscious. People prefer lower cost alternates as compared to luxury products and branded milk is perceived as a luxury product by the mass market of Pakistan.

The third important factor is the price difference between loose milk and branded milk. As dairy companies purchase raw milk from farms and process \& pack it for sale, the end consumer price of branded milk is significantly higher as compared to loose milk. For example, currently, the end consumer price of loose milk is around Rs.50-55/Ltr while branded milk is at + Rs. 70/Ltr. Due to this main factor, demand for fresh milk is high compared to packed milk and fresh milk is the primary dairy product traded in the country (Zia, 2007). This is also the key reason that branded milk is less than $4 \%$ of the total milk production of the country (TetraPak, 2010). It is also important to note that the purchasing price of raw milk (as an item of raw material for dairy manufacturers) has also increased substantially over the past years. A study conducted by Zia in 2007 shows that this price increased from a mere Rs. 20/Ltr to Rs. 32/Ltr in 2007. It is also essential to mention that with growing inflation, this price imbalance has led many large famers to pull out of this sector and it also has discouraged further investment in dairy production (Zia, 2007). A fourth important factor is the cost investment \& heavy logistics cost involved in dairy milk collection. For this purpose, we will take a brief overview of the milk collection network. In Pakistan, Punjab and Sindh are the key milk producing provinces. However, most dairy companies are 
operational, primarily in Punjab. Collection centers in Sindh are challenging due to socio-economic constraints such as road conditions and safety. This fact has led the companies to set up additional collection units in key areas of Punjab (Zia, 2007). Furthermore, in order to acquire the lowest possible prices of raw milk, companies are also increasing their accessibility to farmers in far flung areas. In these areas, farmers do not have access to the urban retail market which could be more profitable for them. However, accessing these far flung areas increases the transportation and logistics cost. Further, long spells of hot weather (fresh milk has a shelf life of approximately three-four hours under normal temperatures) prevent it from reaching the milk collection centers and factory premises on time (Rizvi, 2000).

A fifth important factor is the rising price of packaging. TetraPak packaging is a key cost involved in the production of branded milk. As the price of TetraPak packaging is increased upto three times a year, these results in a consistent increase in end consumer price of the milk brands. Hence, a large number of middle income consumers cannot easily afford increased rates of TetraPak milk brands (Sher, 2010). Hence, it is also a challenge for dairy product manufacturers to consider how new packaging solutions can be introduced, so that packed milk of good quality can be marketed in an inexpensive manner to a large portion of the consumer market (Fakhar, 2006). Furthermore, generating economies of scale is also a necessity in this sector as it is believed globally that a "leaner" yet 'larger' dairy sector is more productive than farms on a small scale (Narasimhan, 2011). Keeping the above factors in mind, it is deduced that dairy product manufacturers are facing high cost pressures, resulting in a pressed bottom line. The evidences from the literature given above serve as a basis for the primary survey conducted for this article.

Broad Problem Area and Problem Statement: Based on the review of relevant literature, the broad problem area is cost pressures on dairy product manufacturers in Pakistan. Further analysis has been done to identify the key cost components and their level of impact in the study industry. Subsequently, in order to make the study useful and meaningful for business managers, the cost minimization techniques have also been discussed with their level of importance. Hence, the problem statement is Cost Minimization Techniques in Dairy product manufacturers in Pakistan.

\section{Objectives of Research}

Main Objective: The main objective of the study is to study the key cost components \& cost minimization techniques of dairy product manufacturers in order to provide future direction for decision makers and further opportunities for research.

Sub Objectives: In line with the main objective, the following sub objectives have been be studied:

- To find the cost components/determinants in the dairy industry of Pakistan.

- To ascertain the level of impact of these cost determinants on profitability.

- To identify and discuss the techniques used by the dairy manufacturers to minimize costs or maximize profits.

- To gauge the level of impact of the identified cost minimization techniques on the profitability of the company

- To suggest further areas for improvement.

\section{Methodology}

Purpose \& Type of study: This is a descriptive study as it has been undertaken to describe the characteristics of interest (cost components and their impact) in a particular industry. It describes the level of impact of these components as well as the measures taken to minimize costs, in order of importance. This research hence, offers ideas for further probing and a guideline for managers in the dairy industry of Pakistan.

Data collection \& Study Setting: Interviews were conducted with respondents face to face, in their respective premises/offices while some managers were also emailed the questionnaires for their response. The questionnaire included a combination of nominal, ordinal, ratio \& interval scales in order to fulfill the objectives. Some parts of the questionnaire were also kept open ended (particularly the section related to cost components and cost minimization techniques), in order to highlight responses from managers regarding reasons for providing a particular rating, industry specific insights and 
recommendations. The study setting is Non-contrived and the researcher interference is Minimal as the respondents were fully allowed to explicitly highlight their opinion on the subject. Hence, it can be termed as field experiment (non contrived + minimal interference). The data analysis has been conducted in SPSS software.

Sampling Technique \& Sample size: The unit of analysis is corporate/central line managers from companies in the dairy industry of Pakistan. As there are limited number of dairy companies in Pakistan and approximately $90 \%$ market share is with the top 4 players (TetraPak, 2010), the sample size has also been limited to the managers of these top companies. The sample size is 42 managers from these companies. It is important to highlight once again that these 42 managers represent majority of the branded dairy industry due to the reason cited above. The managers are all part of the middle to senior tier management of their respective companies. Out of the total; 18 managers belong to the Finance department, 12 managers to Marketing and 6 manages each belong to the Operations and Milk procurement departments. All these departments are central departments of their respective companies and are directly relevant to the requirements of this research. Type of sampling used was Non-probability sampling as it was imperative that the managers must belong to one of the leading dairy companies. Here, factors of time \& cost were also critical. A Purposive sampling technique was implied whereby the researcher used judgment sampling to select the most relevant companies and respondents in order to fulfill the objectives.

\section{Data Analysis \& Results}

Profile of Respondents: As discussed in the sampling methodology, there are currently 4 major branded milk manufacturing companies in Pakistan which represent $90 \%$ of the total packaged milk industry. Data has been gathered from a total of 42 respondents from these four companies. These respondents represent leading departments including Finance, Marketing, Operations \& milk procurement. The reason for selection of these departments is that they are directly involved with the cost management and profit generation of the company. Overall, $43 \%$ managers belong to the Finance department, $29 \%$ from the Marketing department while $14 \%$ each are from the Operations and milk procurement departments.

Table 1: Respondent Department

\begin{tabular}{llllll}
\hline & & Frequency & Percent & Valid Percent & Cumulative Percent \\
\hline Valid & Finance & 18 & 42.9 & 42.9 & 42.9 \\
& Marketing & 12 & 28.6 & 28.6 & 71.4 \\
& Operations & 6 & 14.3 & 14.3 & 85.7 \\
& Milk procurement & 6 & 14.3 & 14.3 & 100.0 \\
& Total & 42 & 100.0 & 100.0 & \\
\hline
\end{tabular}

It was ensured that all of the respondents belong to middle cadre or above and are decision makers in their respective divisions. Hence, highest possible accuracy has been assured in the research. Overall, $57 \%$ respondents are senior managers while $43 \%$ managers belong to the middle tier of management, in their respective companies.

Table 2: Respondent Tier of Management

\begin{tabular}{llllll}
\hline & & Frequency & Percent & Valid Percent & Cumulative Percent \\
\hline Valid & Middle Tier & 18 & 42.9 & 42.9 & 42.9 \\
& Senior Tier & 24 & 57.1 & 57.1 & 100.0 \\
& Total & 42 & 100.0 & 100.0 & \\
\hline
\end{tabular}

Cost Components and their Impact: The managers were asked to rate key cost components in terms of their impact on determination of profit. The key cost factors for the dairy industry are raw milk (purchased from farms and then processed \& packed), other raw material, packaging cost (mainly TetraPak/flexible pouch packing), labor cost, factory overheads, marketing investments, selling and distribution costs, administrative costs and managerial human resource costs. These cost factors/components were rated by the managers on a likert scale of 1-5 (1 meaning 'No impact; and 5 meaning 'Very high impact'). The impact of raw milk cost on profitability comes out to be the highest. It 
has a mean score of 4.7 implying that it is close to 'Very high impact'. This is quite acceptable as raw milk is purchased/sourced/gathered from the farms by the manufacturing concerns and then processed and packed in final form (branded milk, yogurt, butter, cheese, butter oil etc.). It was highlighted by the managers that even a slight increase in the price of raw milk results in a multifold increase in the manufacturing costs of the range of products. The minimum rating for this component is 4 and standard deviation is 0.45 , which shows consistency in the responses from all managers.

Table 3: Impact of Cost components

\begin{tabular}{llllll}
\hline & $\mathbf{N}$ & Min. & Max. & Mean & Std. Deviation \\
\hline Impact of Raw Milk cost & 42 & 4.00 & 5.00 & 4.7143 & .45723 \\
Impact of Other Raw Material & 42 & 3.00 & 4.00 & 3.5714 & .50087 \\
Impact of Packaging Cost & 42 & 3.00 & 5.00 & 4.1429 & .64662 \\
Impact of Labor cost & 42 & 1.00 & 3.00 & 2.5714 & .73726 \\
Impact of Factory Overheads & 42 & 1.00 & 3.00 & 2.5714 & .73726 \\
Impact of Marketing costs & 42 & 3.00 & 5.00 & 3.7143 & .70834 \\
Impact of Selling \& Dist cost & 42 & 2.00 & 5.00 & 3.7143 & .89131 \\
Impact of Administrative cost & 42 & 1.00 & 3.00 & 2.2857 & .70834 \\
Impact of HR costs (Managerial) & 42 & 1.00 & 3.00 & 2.2857 & .70834 \\
\hline
\end{tabular}

The second most important cost component is the packaging cost, having a mean rating of 4.14. In most cases, this is mainly due to the cost of TetraPak's packaging. As highlighted by the managers, this particular packaging is 6 layered and protects the milk from sunlight, moisture, dampness, germs, bacteria etc. However, having its distinct benefits and based on extensive research and development, TetraPak packaging also carries a heavy price tag. Further, frequent price increases of the packaging are also prevalent, as identified in the literature. Apart from this primary packaging, it was shared by the respondents that secondary packaging (outer cartons) also incurs considerable cost, although much lower than TetraPak in terms of per unit cost. The third most significant costs affecting the profits of these dairy companies are marketing, selling and distribution costs (covered separately but having the same mean score of 3.71 in this research). It was shared by the respondents that as the various brands of the leading companies have close market shares and high competition is prevalent, heavy investment is required in the areas of consumer marketing. Hence, the companies invest mainly in the areas of creative advertising, media airing, direct marketing activities and marketing research. Similarly, it was mentioned by most respondents that there is high competition in building market and trade presence. Main investment includes enhancing distribution channels, expanding product availability on a nationwide basis and new town development. Further, heavy investment is also required in terms of attractive trade offers to the retailers and wholesalers.

Other raw material has also been identified as one of the key cost factors. This component has a mean score of 3.57 and standard deviation of 0.5 . This implies moderate impact on profitability, as the main influencer is raw milk. Labor and factory overheads have a mean of 2.57 each and standard deviation of 0.7. This implies slight impact on profitability. It is important to mention here that these two components have a significant contribution in most industries. However, in the dairy sector, these factors are more consistent in nature while other 'industry specific' components including raw milk \& packaging cost are more significant \& demanding cost components. Impact of administrative costs and managerial human resource costs on profitability is 'slight' in nature, having a mean rating of 2.28 and minimum rating of 1 . As mentioned by the respondents in the interviews, due to the highly competitive nature of the industry, dairy companies regard managerial human resource costs as an important investment, being only a small part of the total cost. Similarly, administrative costs are also slight or low in terms on their impact on overall profitability.

Cost Minimization techniques and their Impact: Perhaps, the most important section of this research is presentation of the cost minimization techniques used by companies in the dairy sector as well as the impact level of these techniques on profitability. These findings present a useful guideline to new entrants and existing companies on how to maximize their profits, through various cost minimization methods. 
Table 4: Impact of Cost Minimization Techniques

\begin{tabular}{llllll}
\hline & N & Minimum & Maximum & Mean & Std. Deviation \\
\hline Frequent price increases & 42 & 2.00 & 5.00 & 4.2857 & 1.17465 \\
Product formulation & 42 & 2.00 & 5.00 & 3.7143 & 1.04264 \\
Alternative packaging & 42 & 2.00 & 5.00 & 4.0000 & 1.08200 \\
Declared Under filling & 42 & 2.00 & 5.00 & 3.4286 & .91446 \\
Operational efficiency/Reduce machine & 42 & 1.00 & 5.00 & 3.2857 & 1.29324 \\
downtime & 42 & 2.00 & 5.00 & 3.5714 & 1.19231 \\
Economies of Scale & 42 & 1.00 & 5.00 & 3.2857 & 1.40184 \\
Control expenses of electricity, fuel etc. & 42 & 1.00 & 5.00 & 2.5714 & 1.19231 \\
Reduce Marketing investment & 42 & 1.00 & 3.00 & 2.1429 & .84309 \\
Reduce Margins to retailers & 42 & 2.00 & 5.00 & 3.4286 & .91446 \\
Efficiency through Bulk buying & 42 & 2.00 & 5.00 & 3.5714 & .91446 \\
Increase negotiation with suppliers & 42 & 2.00 & 5.00 & 3.0000 & .93704 \\
Reduce administrative costs & 42 & 2.00 & 3.00 & 2.4286 & .50087 \\
Downsizing (Labor) & 42 & 2.00 & 3.00 & 2.2857 & .45723 \\
Downsizing (Managers) & 42 & 2.00 & 4.00 & 2.8571 & .84309 \\
Freeze Hiring of new staff & 42 & 2.00 & 5.00 & 2.7143 & 1.04264 \\
Curtail Benefits & & & &
\end{tabular}

The respondents were asked to rate the impact level of these measures for the dairy industry, in terms of their contribution in profit. A likert scale of 1-5 was used whereby 1 means no impact and 5 means very high impact. The identified measures to increase profits/reduce costs were: frequent price increases, changes in product formulation (recipe), exploring alternate packaging options, reducing contents/filling/pack size (with declaration), controlling machine down time/increasing operational efficiency, gaining efficiencies through economies of scale (bulk production), control expenses on electricity, gas/utilities, reduce marketing investment, reduce margins to retailers, efficiencies through bulk buying (raw material, packaging, media), increase negotiation amongst suppliers \& vendors (for lower quotes), reduce administrative costs, initiate downsizing (Labor), initiate downsizing (managers), freeze hiring of new staff, curtail promotions, perks, benefits etc. Following are the detailed findings of each technique in detail:

Regular Price Increases: The research shows that the tool having the most \& direct impact on profitability of dairy companies is simply increasing the prices of products. Thus, the mean score of this measure is 4.28, implying 'High impact'.

Alternative packaging: With regards to packaging, as discussed earlier, most companies pack their milk products in TetraPak packaging, which is an expensive option. Hence, the managers explained that many companies have also explored alternate modes of packaging, for example pouch packaging for pasteurized milk, bottled milk etc. This is the second most important measure for the dairy companies in terms of impact; resulting in mean rating of 4.0 (high impact).

Product formulation: The third most important factor is change in product formulation or recipe. The managers shared that the recipe is optimized according to consumer preferences and according to food laws, as well as cost factors. This measure acquires a rating of 3.7 (implying moderate to high impact).

Economies of Scale: Economies of scale come out as an important method to create cost efficiencies. The managers have assigned this approach, a mean rating of 3.57 which means moderate impact on profitability. The managers shared that due to the immense market demand and fast moving nature of their products, planning and production takes place on a massive scale, daily. This also results in reducing the fixed costs of the business unit.

Increasing negotiation with suppliers: Increasing negotiation with suppliers also appears as a significant factor, having the same mean score as economies of scale. According to the respondents, 
acquiring competitive quotes and blind quotations from multiple suppliers results in competition in the suppliers and hence reduces the cost of inputs, material and services. Direct negotiation further drives down the cost. Due to the high volume business of these dairy giants, increased efficiency from the supply end results in overall substantial savings for the company.

Efficiencies through bulk buying: Another important cost reduction measure is generating efficiencies through bulk buying. This method has a mean rating of 3.4 (moderate impact) and standard deviation of 0.91 which shows consistency in the responses. The respondents mentioned that bulk buying is an important method of reducing costs in the areas of raw material, packaging and even media. Bulk buying results in heavy initial cash outlay but results in lowering costs in the medium term and is especially justified for fast moving inputs/raw material.

Declared Under filling of products: Another technique used by dairy product manufacturers is under filling of products with on pack declaration. This also has the same mean rating as bulk buying. The managers shared that in case of some of their products, for example $250 \mathrm{ml}$ milk pouches, the milk content was reduced to $240 \mathrm{ml}$ and the revised label of ' $240 \mathrm{ml}$ ' was of course also printed on the packaging. This is used as an alternate to increasing the price.

Controlling machine downtime/Operational efficiencies: The respondents allotted a mean score of 3.28 to controlling machine downtime and gaining operational efficiencies. This factor hence as a moderate impact on profitability of the company. It was explained by the respondents that proper preventive maintenance of the machines reduces the probability of a machine breaking down, during, before or after production. Further, a regular inspection and maintenance schedule increases the operational efficiency of the plant/factory.

Controlling expenses on utilities (electricity, gas etc): Apart from the above, controlling expenses on utilities including electricity, gas etc. also has a mean score of 3.28. While this component results in substantially high costs, it has been given a moderate rating by the managers as it is quite an uncontrollable factor for the management of the company.

Reducing administrative costs: Reducing administrative costs has acquired a mean rating of 3 and a minimum rating of 2 , making it closer to low impact. The respondents mentioned that administrative cost reduction is an easy and visible way to reduce costs but is only a very small percentage of the company's overall costs.

Freeze hiring of new staff \& curtailing benefits: Amongst the low impact measures, freezing hiring of new staff comes out on top. It has a mean rating of 2.8 with a standard deviation of 0.8 . This measure is preferred by managers as opposed to downsizing as it helps in retaining the existing workforce while keeping a constraint on human resource costs. The managers also explained that hiring new human resource talent always results in increased HR costs; hence it is preferred to retain \& motivate the existing talent pool. Curtailing benefits acquired a mean score of 2.7 which means low impact on profitability.

Reducing Marketing investment: As discussed earlier, due to the highly competitive nature of the dairy sector, heavy marketing investment is required by the companies in order to increase consumer demand of their products. The managers explained that although the marketing investment is a substantially high amount, it cannot be reduced altogether as it is necessary for maintaining and increasing market share of their products. Hence, the mean score of impact of reducing marketing investment is also a 2.57 (slight impact) with a minimum rating of 1 .

Downsizing (Labor \& Managerial): In the current era, downsizing is a common practice used by companies in order to reduce costs in the short term. However, according to our research, the managers have assigned a mean rating of 2.4 to downsizing of labour and 2.2 to the downsizing of managerial staff. Most managers commented that human resources are the key to driving the business successfully and employees in the dairy sector possess highly specific skills which are beneficial for the company as well. Hence, it is preferred not to downsize. Further, this measure has only a slight impact on the overall profitability as it is only a small percentage of the overall costs. In addition, downsizing of managers (as opposed to factory workers) is the last resort as there are a limited number of highly trained managers in the dairy sector of Pakistan. 
Reducing margins of retailers: The cost reduction measure having the least impact on profitability of the company is reducing the profit margins of the retailers. This tool has a mean score of 2.14 and minimum rating of 1 , making it close to no impact. The reason cited by the respondents was that retailers are key partners in ensuring sales of the products. If the margin is reduced, they will reduce their cooperation with the company or might prefer to trade the competitor's products. Hence, it is best that this measure is avoided, although it involves substantial investment. Overall, the cost minimization techniques discussed above can prove useful to researchers and corporate decision makers in the dairy sector of Pakistan.

\section{Conclusion}

The research study shows that cost minimization is no doubt a primary requisite for dairy product manufacturers in Pakistan. The findings have been presented based on a detailed primary survey conducted with managers in top dairy companies of Pakistan. The major cost component in the dairy sector is raw milk which is collected from dairy farms across the country. The second cost component having a major impact on profitability is the cost of reliable packaging followed by marketing, distribution, other raw material, labor \& factory overhead costs. Each cost has been discussed separately in detail. In this study, a multitude of cost minimization or profit maximization techniques have been discussed along with their impact on profitability. Techniques having a +high impact include regular price increases and exploring alternate, cost effective packaging options. Measures with a moderate impact include optimizing the product formulation, generating economies of scale, creating efficiency through bulk buying, declared under filling, controlling machine downtime, gaining operational efficiencies and curtailing expenses on utilities including electricity, gas etc. Techniques having a relatively slight impact on profitability include freezing new staff hiring, reducing marketing investment, downsizing and curtailing benefits \& perks of the employees. Reducing margins of the retailer comes out as the least preferred cost reduction technique as it can have an adverse effect on the sales of the company. In addition to the above, substantial recommendations have also been provided on how to minimize cost pressures faced by the dairy companies. It can be concluded that while there are multiple challenges for dairy product manufacturers in the current economic scenario of Pakistan, this research article presents a practical guideline for decision makers in the dairy industry on how to maximize profits through cost minimization. This article presents ample opportunities for further research studies in this area as it is the first article on the topic in Pakistan and covers key areas including cost components and their impact as well as priority wise cost optimization techniques in one of the highest growth sectors of the country.

Limitations of the Study: As this research has been conducted with corporate managers in the dairy industry, it cannot be replicated to other industries. Furthermore, the respondents are high profile, middle to senior level corporate managers from leading departments of top dairy companies. There are a limited number of managers fitting this profile in Pakistan. Hence, the sample size is 42 such managers who represent the top 4 companies (these companies contribute $90 \%$ volume of the branded milk industry of the country).

Recommendations: The respondents were also asked to provide their recommendations in an open ended section of the questionnaire. While they mentioned that most of the subject matter has already been discussed, the following new ideas/avenues were also highlighted:

- The dairy development sector of the Government should extend loans on easy terms to dairy farmers, across the country. This shall increase the level of yield and thus product manufacturers will not have to go to far flung areas for milk collection.

- Companies facing high cost pressures can re-evaluate their business size. For example, national companies can focus on few regional markets, in order to optimize operational costs.

- Alternate vendor sources from foreign countries (including China) can be explored for better cost efficiencies.

- Companies should keep focusing on existing products and brands rather than trying to diversify in the economic downturn. Going aggressive may not always be the right approach in achieving long term success of a business.

- Smaller SKUs (stock keeping units) can be introduced on power price points (for example, Rs. 5 \& 10 ) in order to generate better acceptability in the lower tier of the market and enhancing the sales base.

- Cost optimization can also be achieved through enhancing process efficiency and bringing better technology into the process. 
- Research studies can be conducted in neighboring countries with similar market dynamics (for example India) in order to increase level of know-how and expertise on the subject.

- There should be increased focus on integration especially backward, for the procurement of Raw Milk. This can include self dairy farming and long term contracts with farmers for investment in their farms, providing the required infrastructure \& machinery. It will result in healthier live stock and will also reduce costs in the long run.

- There should not be high reliability on a single packaging material supplier and alternative companies should be invited to the country.

- The dairy companies should focus their sales primarily on the retail market and less on the wholesale market as additional discounts have to be given to the wholesalers, further driving down the bottom line of the products.

- There should be limited intermediaries/middle men in order to avoid extra costs and better margins can be achieved by forward integration as well. For example, setting up company operated milk shops, near the factory.

\section{References}

Afzal, M. (2006). Investment opportunities in livestock sector in Pakistan. The News

Corporate author. (2011). Significance of livestock and dairy sector in Pakistan. The Dawn

Corporate author. (2011). Dairy Industries in Pakistan. Retrieved from http:// www.pakissan.com/ english/allabout/ livestock/ dairy/dairy.industries.in.pakistan.shtml

Fakhar, H. (2006). The White Revolution - Dhoodh Darya. Publication of Pakistan Dairy development.

Grossberg, K. A. (2009). Marketing in the Great Recession: an executive guide. Strategy and leadership

Narasimhan, K. (2011). Optimizing Factory Performance: Cost Effective Ways to Achieve Significant and Sustainable Improvement. The TQM Journal, 23(5), 578 - 579.

Rizvi, A. (2000). The Dairy Industry. Pakistan Economist issue 2000/21

Rizvi, A. (2002). Boosting dairy and meat production. Pakistan Economist issue 2002/29

Saul, B., Steven, D., Sara, L. \& Amy, B. (2009). Succeeding in the new economic environment - three targets for leaders. Strategy and leadership

Sherani, S. (2009-10). Economic Survey of Pakistan

Sher, T. (2010). Tetra pak milk prices increase before budget. Daily times

Tetra Pak Dairy Index issue. (2010). Biannual news and information source about the dairy industry.

Zia, U. S. (2007). Improved Market Access and Smallholder Dairy Farmer Participation for Sustainable Dairy Development. 